\title{
Sites of Synthesis of Encephalomyocarditis Virus Components in Infected L-Gells
}

\author{
By A. J. D. BELLETT,* R. G. HARRIS AND F. K. SANDERS \\ Virus Research Unit, M.R.C. Laboratories, Carshalton, Surrey, England
}

(Received 12 November 1964)

\begin{abstract}
SUMMARY
L-cells were fractionated at various times after infection with EMC virus and assayed for haemagglutinin, virus and phenol-extractable infective RNA. A second fraction of infective RNA was obtained by sodium dodecyl sulphate (SDS) extraction of the samples after phenol extraction. The infectivity of SDS-extracted RNA increased earlier than that of phenol-extracted RNA, but the maximum titre was less than $10 \%$ of the maximum titre extracted by phenol. The early rise in SDS-extracted RNA was largely confined to the nuclear fraction, and the infectivity of phenol-extracted RNA appeared to increase in the nuclear fraction before the cytoplasmic fraction. There was a simultaneous increase in the titres of both fractions of RNA, haemagglutinin and virus in the cytoplasmic fraction from 3 to $5 \mathrm{hr}$ after infection, and the maximum titres of infective RNA were found in the cytoplasm $4-5 \frac{1}{2} \mathrm{hr}$ after infection. It was concluded that synthesis of viral RNA begins near the nuclear membrane and then spreads outwards through the cytoplasm, but that there is no conclusive evidence as to whether this process begins in the nuclei or the perinuclear cytoplasm.
\end{abstract}

\section{INTRODUCTION}

Synthesis of viral ribonucleic acid (RNA) 1-2 hr before the appearance of intracellular virus has been reported during replication of mouse encephalomyocarditis (EMC) virus in Krebs-2 ascites tumour cells, and of mouse encephalitis virus in L-cells (Sanders, 1960; Martin \& Work, 1962; Hausen \& Schäfer, 1961). It was recently suggested that infective RNA was first produced in the nuclei of ascites cells during the $4 \frac{1}{2} \mathrm{hr}$ after infection with EMC virus, and that the RNA was then transferred to the cytoplasm and there initiated the production of haemagglutinin and plaque-forming virus (Bellett \& Burness, 1960, 1963).

In L-cells infected with mengo virus, both acridine orange staining and autoradiography with tritiated uridine indicated that new $\mathrm{RNA}$ accumulated in the perinuclear cytoplasm just before the appearance of viral antigen; this suggested that viral RNA was synthesized in the cytoplasm shortly before the viral protein (Franklin, 1962; Franklin \& Rosner, 1962; Franklin \& Baltimore, 1962). This apparent difference between the replication of EMC virus and mengo virus was unexpected, since the two viruses are very closely related (Dick, 1949; Warren, Smadel \& Russ, 1949).

* Present address: Department of Microbiology, John Curtin School of Medical Research, Australian National University, Canberra, Australia.

Vol. 38, No. 2 was issued 8 March 1965 
Dulbecco (1962) thought that such a fundamental difference was unlikely to be real, and noted a similar discrepancy in the apparent sites of synthesis of myxovirus soluble antigens. He proposed that the nucleic acid of all RNA viruses is synthesized in the nuclei of infected cells, any apparent exceptions being due to very rapid transfer of the RNA to the cytoplasm. He concluded that RNA could be transferred from nucleus to cytoplasm fast enough to give Franklin's results, since intercellular transfer of DNA occurs at a similar rate during bacterial conjugation. According to this hypothesis, RNA did not accumulate in the nuclei of L-cells infected by mengo virus because transfer of viral RNA to the cytoplasm was faster in L-cells than in Krebs-2 ascites cells infected by EMC virus, synthesis of RNA being nuclear in both systems.

Experiments reported in this paper were designed to test this hypothesis by a study of the replication of EMC virus in L-cells. The results were consistent with the hypothesis but were not conclusive. Since the work was completed, further evidence for the cytoplasmic synthesis of RNA by small riboviruses has been published (Holland \& Bassett, 1964; Horton et al. 1964). The present position is briefly reviewed, and it is concluded that RNA synthesis by small riboviruses begins near the nuclear membrane and then spreads outwards through the cytoplasm, but that there is no conclusive evidence as to whether this process begins within the nucleus or in the perinuclear cytoplasm.

\section{METHODS}

\section{Growth of virus in L-cells}

L-cells $\left(10^{8} / \mathrm{ml}\right.$. in Eagle's medium) were infected with 5 plaque-forming units (p.f.u.)/cell of EMC virus (K-2 strain) for $30 \mathrm{~min}$. at $4^{\circ}$, centrifuged for $5 \mathrm{~min}$. at 900 $\mathrm{rev} / \mathrm{min}$. and resuspended to $10^{7} \mathrm{cells} / \mathrm{ml}$. in warm $\left(37^{\circ}\right)$ Eagle's medium containing $5 \%(\mathrm{v} / \mathrm{v})$ heat-treated $\left(60^{\circ}, 30 \mathrm{~min}\right.$.) calf serum. The infected cells were maintained in suspension at $37^{\circ}$ and sampled at intervals. Samples were pipetted into about 10 vol. of ice-cold phosphate-buffered saline without calcium or magnesium, centrifuged, washed and either stored at $-20^{\circ}$ or used for preparation of sub-cellular fractions.

\section{Preparation of subcellular fractions}

The fractions were prepared at $0-4^{\circ}$. Infected cells $\left(3\right.$ to $\left.5 \times 10^{7}\right)$ were washed with $1 \mathrm{ml}$. 0.001 M-disodium ethylenediaminetetra-acetate (EDTA, pH 7.0), and then disrupted and separated into nuclear and cytoplasmic fractions by the method of Fisher \& Harris (1962). The preliminary wash in hypotonic EDTA decreased to $20 \mathrm{~min}$. the time necessary to obtain a clean nuclear fraction without significantly affecting the recovery of nuclei, although it may have caused some loss of nuclear soluble RNA (Srinivasan, Miller-Faures \& Errera, 1962). Small tags of cytoplasm were seen by phase-contrast microscopy on 5-10\% of the nuclei. The fractions were stored at $-20^{\circ}$

\section{Preparation of phenol-extracted $\boldsymbol{R} N \boldsymbol{A}$}

RNA was prepared by two phenol extractions in $0 \cdot 1 \mathrm{M}$-acetate buffer, $\mathrm{pH} \mathrm{6.0,}$ containing 0.05 M-EDTA and $2 \%$ bentonite (Fraenkel-Conrat, Singer \& Tsugita, 1961). The RNA was twice precipitated by ethanol and stored at $4^{\circ}$ in $67 \%$ ethanol. RNA samples were dissolved in $1 \mathrm{ml}$. 0.2 $\mathrm{M}$-phosphate buffer, $\mathrm{pH} 6 \cdot 8$, just before use. 


\section{Sodium dodecyl sulphate (SDS)-extracted $R N A$}

A second fraction of infective RNA can be obtained by SDS extraction of the layer remaining at the interface between the aqueous and phenol layers after the first phenol extraction (Montagnier \& Sanders, 1963). The interfaces and the underlying phenol layers were first washed with $5 \mathrm{ml} .0 \cdot 1 \mathrm{M}$-acetate buffer, $\mathrm{pH} \mathrm{6.0,} \mathrm{con-}$ taining $0.05 \mathrm{M}$-EDTA, and then shaken with $5 \mathrm{ml}$. of the same solution containing $2 \%(\mathrm{w} / \mathrm{v})$ SDS. The preparation was completed by a second phenol extraction of the SDS supernatant fluid, followed by ethanol precipitation of the RNA as before.

SDS -extracted nucleic acid contained deoxyribonucleic acid and RNA, including a fraction rapidly labelled by ${ }^{32} \mathrm{P}$ (Montagnier \& Sanders, 1963); $89 \%$ of the nucleic acid was derived from nuclei. The bulk of the infective RNA obtained by SDS extraction of infected cells soon after infection had similar properties to the single-stranded viral RNA (Burness et al. 1963), but at later times up to $65 \%$ of the infectivity was in a form which had properties consistent with a double-stranded structure (Montagnier \& Sanders, 1963).

\section{Assay of infectivity}

The infectivity of RNA preparations was determined in Krebs-2 ascites cells by the plaque method of Montagnier \& Sanders (1962). SDS-extracted RNA showed inhibition of plaque formation at high concentrations; the infective titres were therefore calculated from the highest dilutions giving a mean of 5 or more plaques/ plate. Since the variation in recovery of RNA (as measured by extinction at $260 \mathrm{~m} \mu$ ) was small compared with the error in plaque titration of the RNA preparations, the results were expressed simply as p.f.u./ml. of RNA.

Haemagglutinin and virus were assayed by methods previously described (Sanders, Huppert \& Hoskins, 1958; Bellett, 1960).

\section{RESULTS}

\section{Replication of EMC virus in $L$-cells}

The amount of virus which could be recovered from L-cells fell shortly after infection with EMC virus until, at $2 \mathrm{hr}$ after infection, less than $2 \%$ of the cells which registered as infective centres contained detectable plaque-forming virus. New haemagglutinin and virus were first detected at $3 \mathrm{hr}$ after infection, and then increased exponentially until about $6 \mathrm{hr}$ after infection (Fig. 1). Release of virus into the medium began between 4 and $5 \mathrm{hr}$ after infection, and was not complete when the experiments were ended at $7 \mathrm{hr}$.

\section{Early synthesis of infective $R \mathbf{N A}$}

The amount of infective RNA recoverable from L-cells also fell soon after infection, but infective RNA increased in titre 1-2 hr before the virus titre increased (Fig. 1). Infective phenol-extracted RNA increased exponentially from 1 to $5 \mathrm{hr}$ after infection. The infectivity of SDS-extracted RNA seemed to increase more rapidly than the infectivity of phenol-extracted RNA until about $3 \mathrm{hr}$ after infection; this was followed by a slower increase until $5 \mathrm{hr}$ in some experiments. Although SDSextracted RNA was produced before phenol-extracted RNA it did not accumulate to the same extent (Fig. 2), so that the maximum titre of infective SDS-extracted 
RNA was less than $10 \%$ of the maximum phenol-extracted RNA titre (mean of 4 experiments $5 \cdot 7 \%$ ). The highest proportion of infectivity in RNA extracted by SDS was found at $3 \mathrm{hr}$.

\section{Intracellular location of $S D S$-extracted $R N A$}

The early rise in infective SDS-extracted RNA was largely confined to the nuclear fraction (Fig. 3). The infectivity of nuclear SDS-extracted RNA increased from 1 to $4 \mathrm{hr}$ after infection, whereas that of cytoplasmic SDS-extracted RNA did

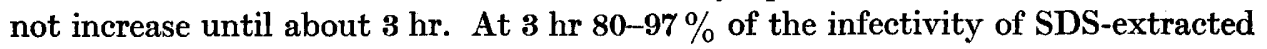
RNA from cell fractions was associated with the nuclear fraction. There was, however, a late increase in the infectivity of cytoplasmic SDS-extracted RNA.

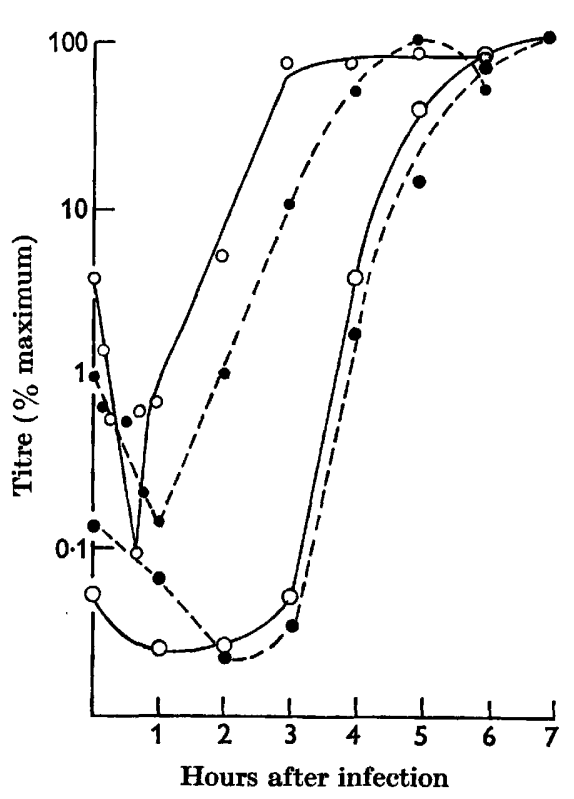

Fig. 1

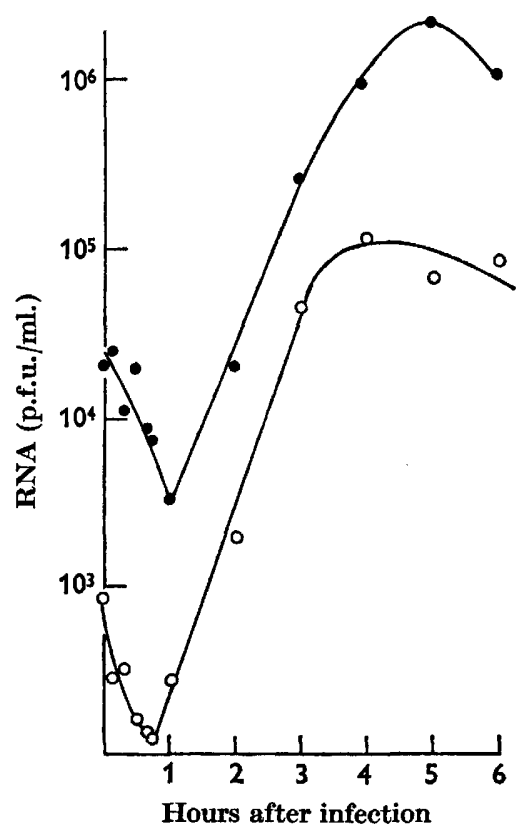

Fig. 2

Fig. 1. Replication of EMC virus components in L-cells. L-cells were infected with EMC virus and incubated in suspension. Samples were removed at intervals and extracted with phenol and then SDS; the RNA preparations were then assayed for infective RNA. Other cell samples were disrupted and assayed for haemagglutinin and plaque-forming virus. The results were expressed as percentages of the maximum yield of each virus component. $\bigcirc-0$, SDS-extracted RNA; $\bullet-. \bullet$, phenol-extracted RNA; $\mathrm{O}-\mathrm{O}$, haemagglutinin;.$--\mathrm{O}$, plaque-forming virus.

Fig. 2. Infective SDS- and phenol-extracted RNA in infected L-cells. Samples of infected cells were extracted with phenol and then SDS. Each RNA sample was dissolved in $1 \mathrm{ml}$. 0.2 M-phosphate buffer, pH 6.8, and assayed for infective RNA. -0 , SDSextracted RNA; $\bullet-\bullet$, phenol-extracted RNA.

\section{Intracellular location of phenol-extracted $\mathrm{RNA}$}

There was no long period of accumulation of infective phenol-extracted RNA in the nuclear fraction of $L$-cells infected by EMC virus, in contrast to our previous results with Krebs-2 ascites cells (Bellett \& Burness, 1963); nevertheless, when the results of several experiments were compared it was found that the increase in 
infective RNA extracted from the nuclear fraction by phenol occurred consistently 30-60 min. before the increase in cytoplasmic infective RNA (Fig. 4). The infectivity of RNA extracted from the nuclear fraction by phenol exceeded that of cytoplasmic phenol-extracted RNA from 2 to about $4 \mathrm{hr}$ after infection, after which the infective RNA was concentrated in the cytoplasmic fraction. The highest proportion of infectivity in RNA extracted from the nuclear fraction was again found about $3 \mathrm{hr}$ after infection. In two experiments over $90 \%$ of the infectivity of phenol-extracted RNA from cell fractions was found in the nuclear fraction at this time (Fig. 5); in other experiments a smaller proportion of the infectivity was found in the nuclear fraction, the mean value being $78 \%$. In one experiment only $45 \%$ of the infectivity was nuclear, but the recovery of infective RNA was poor.

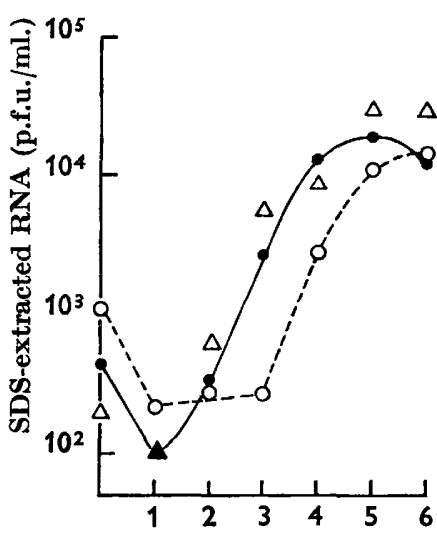

Hours after infection

Fig. 3

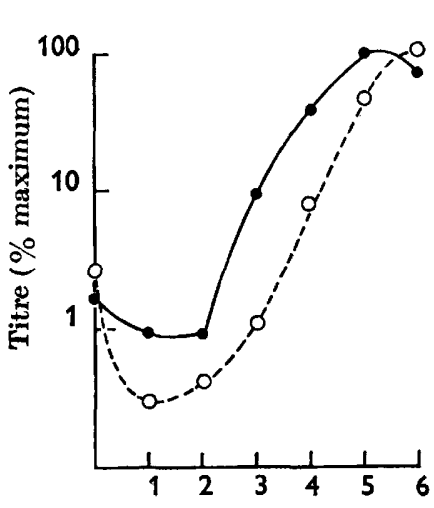

Hours after infection

Fig. 4

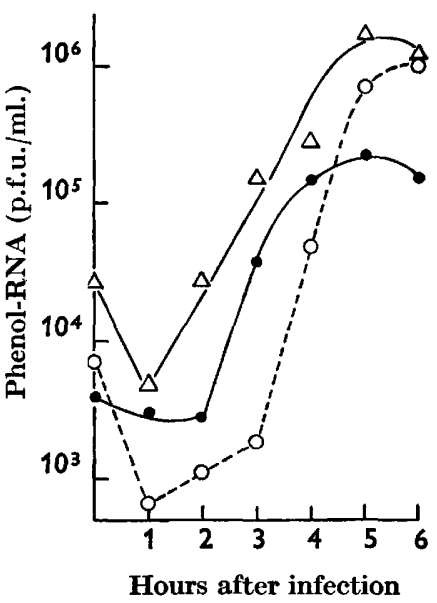

Fig. 5

Figs. 3-5. Location of infective RNA in subcellular fractions of infected L-cells. Samples of infected cells were disrupted and separated into subcellular fractions. The fractions were extracted with phenol and then SDS. Each RNA preparation was dissolved in $1 \mathrm{ml} .0 \cdot 2 \mathrm{M}$-phosphate buffer, pH 6.8, and assayed for infective RNA.

Fig. 3. Infective SDS-RNA in subcellular fractions. O - - O, cytoplasmic SDS-RNA; $\triangle$, whole cell SDS-RNA.

Fig. 4. Infective phenol RNA in subcellular fractions. Results were expressed as percentages of the maximum titre in each fraction; each point is the mean of four determinations. - - Nuclear phenol-RNA; O-- O, cytoplasmic phenol-RNA.

Fig. 5. Infective phenol RNA in subcellular fractions. The results of a typical experiment expressed as p.f.u./ml. RNA. plasmic phenol-RNA; $\triangle \longrightarrow \triangle$, whole cell phenol-RNA.

Recovery of infective phenol-extracted RNA from subcellular fractions was low compared with the amount obtained from whole cells. While it may be concluded that both nuclear and cytoplasmic infective phenol-extracted RNA increased from about 1 to $5 \mathrm{hr}$ after infection, the conclusion that the nuclear increase preceded the cytoplasmic increase depends upon the assumption that the amount of RNA lost from the cytoplasmic fraction did not greatly exceed the amount lost from the nuclear fraction. 


\section{Cytoplasmic production of haemagglutinin and plaque-forming virus}

Both haemagglutinin and plaque-forming virus were produced in the cytoplasmic fraction from 3 to $6 \mathrm{hr}$ after infection (Figs. 6, 7). Haemagglutinin and virus found in the nuclear fraction during this period was probably due to cytoplasmic contamination of the nuclear fraction, since less than $6 \%$ of the haemagglutinin (mean $3.6 \%$ ) and less than $20 \%$ of the virus (mean $14.8 \%$ ) was nuclear at any one time. A higher proportion of both haemagglutinin and virus was apparently

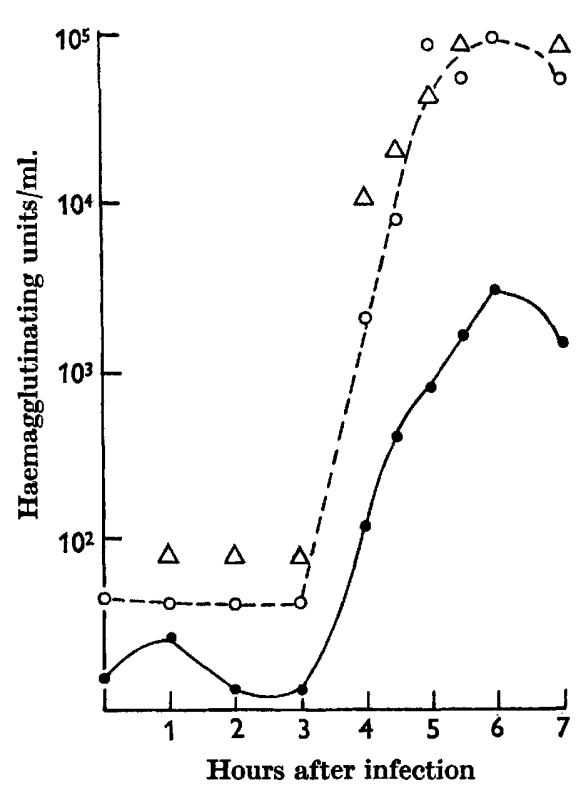

Fig. 6

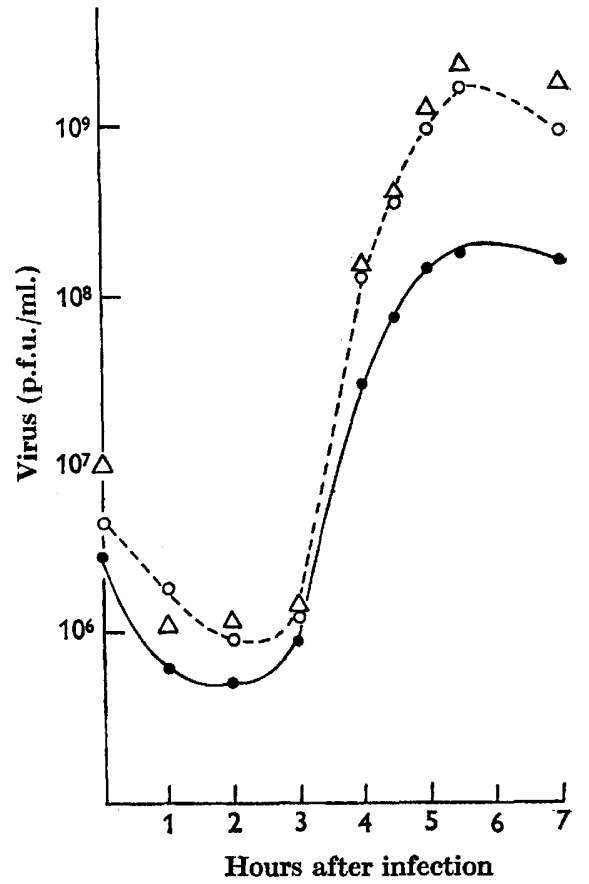

Fig. 7

Figs. 6, 7. Location of haemagglutinnin and virus in subcellular fractions of infected L-cells. Samples of infected cells were disrupted and separated into subcellular fractions. The fractions were further disrupted by shaking with glass beads, clarified and assayed for haemagglutinin and plaque-forming virus.

Fig. 6. Haemagglutinin in subcellular fractions. -O, Nuclear haemagglutinin; $0-.-0$, cytoplasmic haemagglutinin; $\triangle$, whole cell haemagglutinin.

Fig. 7. Virus in subcellular fractions. - - Nuclear virus; $O_{-\cdots}$, cytoplasmic virus; $\triangle$, whole cell virus.

nuclear at $3 \mathrm{hr}$, probably because production of virus began close to the nuclear membrane, so that cytoplasm contaminating the nuclear fraction was particularly rich in virus at this time (Franklin, 1962), but at no time did the proportion of virus in the nuclear fraction approach the high proportion of infective RNA found in that fraction between 2 and $4 \mathrm{hr}$ after infection. 


\section{DISCUSSION}

Results presented in this paper appear to demonstrate that infective RNA increases in titre in the nuclear fraction of homogenates of L-cells infected by EMC virus earlier than in the cytoplasmic fraction, but that the highest titres of infective RNA are found in the cytoplasmic fraction between 4 and $5 \frac{1}{2} \mathrm{hr}$ after infection. The rise in infectivity of phenol-extracted RNA is preceded by a rise in SDS-extracted RNA, which is found mainly in the nuclear fraction from 2 to $4 \mathrm{hr}$ after infection. There is an increase in the titre of SDS-extracted RNA in the cytoplasmic fraction from 3 to $5 \mathrm{hr}$ after infection. Most of the total infectivity of RNA is in the phenol-extractable fraction throughout the growth cycle. The increases in cytoplasmic infective RNA concide with the appearance of virus in the cytoplasmic fraction; but the earlier increases in infectivity of RNA extracted from the nuclear fraction do not appear to be associated with haemagglutinin or virus.

We did not purify our nuclear fraction so that we were able to estimate the recovery of infective RNA in subcellular fractions compared with whole cells. This raises the question of whether the infective RNA found in our nuclear fraction was due to cytoplasmic contamination. While we cannot exclude this possibility, to explain our results by cytoplasmic contamination we should have to assume that the perinuclear cytoplasm was much richer in viral RNA than the rest of the cytoplasm during the $3 \mathrm{hr}$ following infection, and that this position was reversed at later times.

Holland \& Bassett (1964) showed that contamination by cell membranes probably accounted for the infective RNA found in the nuclear fraction of poliovirusinfected cells under conditions which prevented the virus from replicating. Their evidence for cytoplasmic synthesis of poliovirus RNA is not conclusive, however, since their titres of infective RNA were low, they did not include whole-cell controls to estimate the loss of RNA during fractionation, and they did not demonstrate an increase in titre of cytoplasmic infective RNA during replication of the virus.

Zalta, Rozencwajg, Breugnon \& Huppert (1963) observed apparent synthesis of infective RNA by isolated nuclei of cells infected with EMC virus, although Crocker, Pfendt \& Spendlove (1964) showed some incorporation of tritiated uridine into poliovirus-infected enucleate fragments of cells after $7 \mathrm{hr}$ exposure to $5 \mu \mathrm{c} / \mathrm{ml}$. of the label. Experiments in this laboratory (Burness \& Bellett, unpublished) did not show unequivocally synthesis of EMC viral RNA by isolated nuclear or cytoplasmic fractions of infected cells.

Several groups have found increases in RNA-dependent RNA polymerase activity after infection of cells with small riboviruses. In some cases this was found in cytoplasmic fractions but no results were reported for the discarded nuclear fractions (Baltimore \& Franklin, 1962; Baltimore, Eggers, Franklin \& Tamm, 1963). Cline, Eason \& Smellie (1963) showed an increase in RNA-dependent polymerase activity in both nuclear and cytoplasmic fractions of cells after infection by EMC virus. Polymerase activity was cytoplasmic in cells fractionated 4-4 $\frac{1}{2} \mathrm{hr}$ after infection by poliovirus (Holland \& Bassett, 1964), and $5 \frac{1}{2} \mathrm{hr}$ after infection by EMC virus (Horton et al. 1964), but results of fractionation experiments at earlier times were not reported.

Levy (1961) showed increased incorporation of uridine into the nucleoli of cells 
1-3 $\frac{1}{2} \mathrm{hr}$ after infection by poliovirus, and at about the same time the nuclei of the cells stained brightly with fluorescent antibody. At 4-5 hr after infection, the fluorescence was cytoplasmic. Dunnebacke (1962) found enteroviruses only in nucleate fragments of human amnion cells bisected before $4 \frac{1}{2} \mathrm{hr}$ after infection, but in other cells both nucleate and enucleate fragments yielded virus. These experiments indicate nuclear involvement in the replication of small riboviruses, but provide no direct evidence that viral RNA is synthesized in nuclei.

Most of the evidence available at present is consistent with the hypothesis that synthesis of the RNA of the small riboviruses begins close to the nuclear membrane, and then spreads outwards through the cytoplasm. There is as yet no conclusive evidence as to whether RNA synthesis begins within the nuclei of infected cells or in the perinuclear cytoplasm.

We wish to thank Messrs T. Battersby and J. Biffen for maintaining the cultures of L-cells used in this work.

\section{REFERENCES}

Baltimore, D., Eggers, H. J., Franklin, R. M. \& Tamm, I. (1963). Poliovirus induced RNA polymerase and the effects of virus-specific inhibitors on its production. Proc. natn. Acad. Sci., U.S.A. 49, 843.

Baltimore, D. \& Franklin, R. M. (1962). Preliminary data on a virus-specific enzyme system responsible for the synthesis of viral RNA. Biochem. biophys. Res. Commun. 9, 388.

BeLlett, A. J. D. (1960). Use of Pardee's $\mathrm{CO}_{2}$ buffer in plaque titration of EMC virus. Virology, 10, 285.

Bellett, A. J. D. \& Burness, A. T. H. (1960). Sites of synthesis of a nucleic acid and a protein in infected Krebs-2 ascites tumour cells. Biochem. $J .77,17 \mathrm{P}$.

Bellett, A. J. D. \& Burness, A. T. H. (1963). Intracellular sites of synthesis of encephalomyocarditis virus components in Krebs-2 ascites tumour cells. J. gen. Microbiol. 30, 131.

Burness, A. T. H., Vizoso, A. D., Clothier, F. W., Montagnier, L. \& Sanders, F. K. (1963). Encephalomyocarditis virus and its ribonucleic acid: sedimentation characteristics. Nature, Lond. 197, 1177.

Crocker, T. T., Pfendt, E. \& Spendlove, R. (1964). Poliovirus: growth in non-nucleate cytoplasm. Science, 145, 401.

Cline, M. J., Eason, R. \& Smellie, R. M. (1963). The biosynthesis of ribonucleic acid following infection with a ribonucleic acid virus. J. biol. Chem. 238, 1788.

Dick, G. W. A. (1949). The relationship of mengo encephalomyelitis, encephalomyocarditis, Columbia-SK and M.M. viruses. J. Immunol. 62, 375.

Dulbecco, R. (1962). Basic mechanisms in the biology of animal viruses. Cold Spr. Harb. Symp. quant. Biol. 27, 519.

Dunnebacke, T. H. (1962). Amounts of polio and coxsackie viruses within the separate portions of bisected cultured cells. Virology, 16, 392.

Fisher, H. W. \& Harris, H. (1962). The isolation of nuclei from animal cells in culture. Proc. Roy. Soc. B, 156, 521.

Fraenkel-Conrat, H., Singer, B. \& Tsugita, A. (1961). Purification of viral RNA by means of bentonite. Virology, 14, 54 .

Frankiln, R. M. (1962). A cytochemical description of the multiplication of mengo virus in L-929 cells. J. Cell Biol. 12, 1.

Frankits, R. M. \& Baltimore, D. (1962). Patterns of macromolecular synthesis in normal and virus-infected mammalian cells. Cold Spr. Harb. Symp. quant. Biol. $27,175$.

Frankin, R. M. \& Rosner, J. (1962). Localization of ribonucleic acid synthesis in mengo virus-infected cells. Biochim. biophys. Acta, 55, 240. 
Hausen, P. \& Schäfer, W. (1961). Production of virus RNA and virus antigen during multiplication of the ME virus. Z. Naturf. $166 \mathrm{~b}, 72$.

Holland, J. J. \& BassetT, D. W. (1964). Evidence for cytoplasmic replication of poliovirus ribonucleic acid. Virology, 23, 164.

Horton, E., Liv, S. L., Dalgarno, L., Martin, E. M. \& Work, T. S. (1964). Development of ribonucleic acid polymerase in cells infected with encephalomyocarditis virus and the synthesis of single- and double-stranded RNA by the isolated polymerase. Nature, Lond. 204, 247.

LEVY, H. B. (1961). Intracellular sites of poliovirus reproduction. Virology, 15, 173.

Martin, E. M. \& Work, T. S. (1962). Studies on protein and nucleic acid metabolism in virus-infected mammalian cells. 5. The kinetics of synthesis of virus protein and virus ribonucleic acid in Krebs II mouse ascites-tumour cells infected with encephalomyocarditis virus. Biochem. J. 83, 574 .

Montagnier, L. \& Sanders, F. K. (1962). Titrage de l'acide ribonucléique infectieux du virus de l'encéphalomyocardite de la souris sur cellules d'ascite Krebs II in vitro. C.r. hebd. Séanc. Acad. Sci., Paris, 254, 2247.

Montagnier. L. \& Sanders, F. K. (1963). The replicative form of encephalomyocarditis virus ribonucleic acid. Nature, Lond. 199, 664 .

SANDERS, F. K. (1960). Role of infective nucleic acid in the production of encephalomyocarditis virus. Nature, Lond. $185,802$.

SANDERS, F. K., Huppert, J. \& Hoskins, J. M. (1958). Replication of an animal virus. Symp. Soc. Exp. Biol. 12, 123.

Srinivasan, P. R., Miller-Faures, A. \& Errera, M. (1962). Isolation techniques for HeLa-cell nuclei. Biochim. biophys. Acta, 65, 501.

Warren, J., Smadel, J. E. \& Russ, S. B. (1949). The family relationship of encephalomyocarditis, Columbia-SK, M.M., and mengo encephalomyelitis viruses. J. Immun. 62, 387.

Zalta, J. P., Rozencwajg, R., Breugnon, M. M. \& Huppert, J. (1963). Synthèse du RNA infectieux du virus EMC par des noyaux de cellules d'ascite de souris. C.r. hebd. Séanc. Acad. Sci., Paris, 256, 2471. 
